\title{
Development of a geometallurgical model for a copper concentrator
}

\author{
by M. Valenta* and B. Mulcahy*
}

\section{Synopsis}

The purpose of executing a project in a stagewise fashion is to evaluate all potential options in a cost-effective manner and develop an understanding of the project drivers, thereby minimizing overall project risk to the client. Among the more valuable tools for this exercise are production and financial models that can be used to quantify the sensitivity of the project to the critical parameters.

The mine and concentrator used in this case study are located on the Kalahari Copper Belt, which extends from Zambia through northern Botswana into Namibia. This area of Africa has seen very little industrial development and the project will create much-needed employment and development in the region.

The success of this project thus far can be attributed to the close cooperation between the geological, mining, and metallurgical disciplines. Regular updates of projected capital and operating cost estimates coupled with project outputs guided the teams in optimizing their various discipline models, ultimately delivering a compelling argument for the execution of the project. Key to the success was the development of a geometallurgical model for the prediction of concentrate tonnage, grade, and recovery for the life of the mine from the mining plan.

This paper summarizes the metallurgical findings and the outcome of the various project stages. The development of the model is discussed, as are the challenges faced in developing a suitable metallurgical process route.

\section{Keywords}

geometallurgy, Kalahari Copper Belt, modelling, copper, circuit design, stagewise project execution.

\section{Introduction}

\section{The Kalahari Copper Belt}

The Kalahari Copperbelt, which extends from Zambia across northwest Botswana into Namibia, is considered to be a broad time equivalent of the Central African Copperbelt, with a similar style of mineralization. However, at shallower depths $(<25 \mathrm{~m})$, chrysocolla and malachite exist in significant proportions in certain geological areas.

As illustrated in Figure 1, the project is located in the Ghanzi-Chobe Fold Belt which forms part of the Kalahari Copper Belt. The Ghanzi Group, which overlies the lowest stratigraphic unit (the Kwebe Formation), consists of three formations, namely the Ngwako Pan, the D'Kar, and the Mamuno Formation (Hall, 2012).
Mineralization already occurs in the first $10 \mathrm{~m}$ of the D'Kar Formation and is characterized by low-sulphur, low-iron copper sulphides (chalcocite and bornite). The overall genesis of the mineralization resulted from hydrothermal convection cells generated by the high heat flow associated with the thinning, extended continental crust during basin formation. The fluids circulating in these hydrothermal convection cells leached base metals from the underlying Kgwebe formation and produced large volumes of metal-enriched calcareous and siliceous fluids. These fluids then percolated upwards into the highly permeable Ngwako Pan Formation sediments and through them into the base of the less permeable D'Kar Formation, depositing the base metals in disseminated blebs or within thin parallel calcareous and siliceous veins.

Two major areas (Area 1 and Area 2) have been identified in the project that are parallel in a southwest-northeast orientation and are approximately $1 \mathrm{~km}$ apart. The degree of mineral oxidation in Area 1 is significantly higher than in Area 2, and this is attributed to an observed difference in bedding orientation within the deposits (Hall, 2012).

The geologists initially defined three zones in the orebody based on the occurrence of various copper-bearing minerals: the upper zone $(0-25 \mathrm{~m})$, middle zone $(25-35 \mathrm{~m})$, and the lower zone $(>35 \mathrm{~m})$. This definition served its purpose in planning the test work that was required and predicting the relative copper grades and recoveries that could be expected from each zone. On completion of the variability test work the definitions became less relevant when the predictive models were developed based on the mineral content of the ore.

* Metallicon Process Consulting (Pty) Ltd, Ifafi, South Africa.

(C) The Southern African Institute of Mining and Metallurgy, 2016. ISSN 2225-6253. This paper was first presented at the, Copper Cobalt Africa Conference, 6-8 July 2015, Avani Victoria Falls Hotel, Victoria Falls, Livingstone, Zambia. 


\section{Development of a geometallurgical model for a copper concentrator}

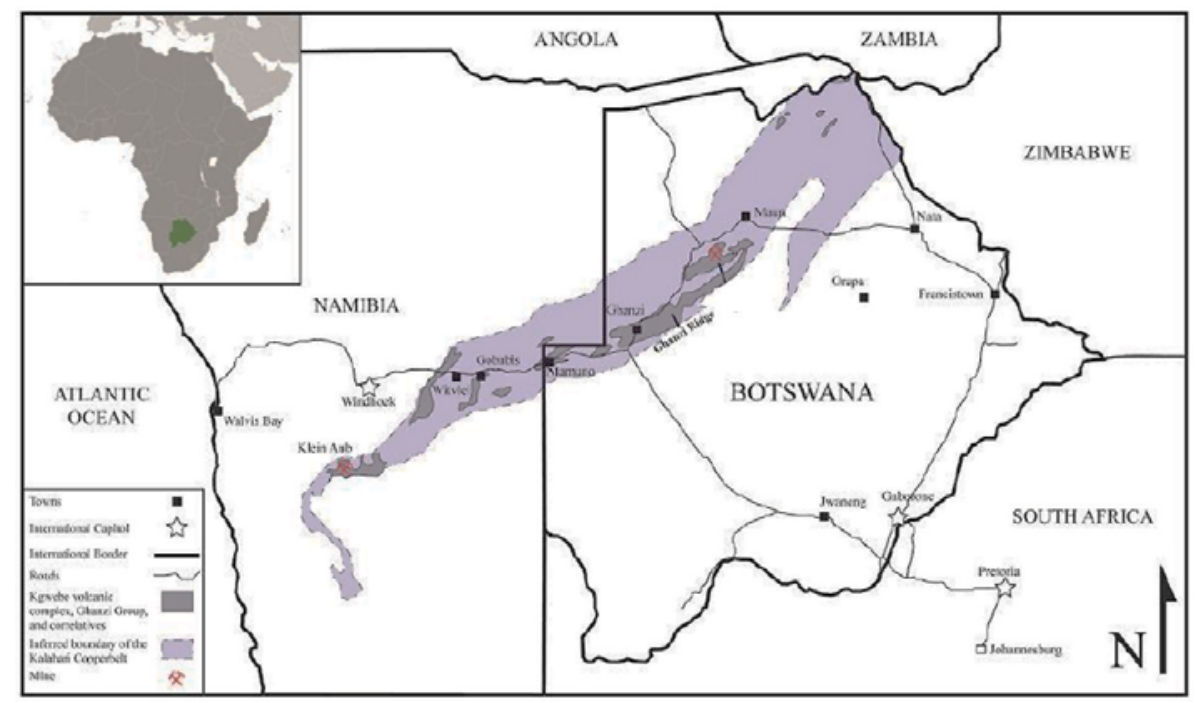

Figure 1-The Kalahari Copper Belt

\section{Country background}

The project area is within $200 \mathrm{~km}$ of the Central Kalahari Nature Reserve and it is not uncommon for game such as lion and elephant to be reported in the region. The project is also in close proximity to Maun, which is regarded as the gateway to the Okavango Delta and is of significant value to Botswana as an ecological gem and a tourist destination.

Furthermore, the project is in an arid region where water is more precious to the local population than the diamonds from the nearby Orapa diamond mine. Throughout the development of the project the team considered all avenues to minimize the consumption of water. Botswana is also dependent on other countries, particularly South Africa, for the supply of electricity. Developments in the resource market have put strain on the supply of electricity throughout the Southern African Development Community (SADC) and for this reason the team had to consider technology that would minimize the consumption of electricity.

\section{Project development}

From the outset the project team planned to use a tollgating approach and develop the project in stages as illustrated in Figure 2.

The objective of such a strategy is to establish formal reporting deadlines, thus allowing the three major project disciplines (geology, mining, and metallurgical) to share information and update the project database. The metallurgical engineers required updates from the geological and mining teams on the latest geological and mining models to refine their metallurgical test work. The mining engineers could then optimize their mining plans to focus on highyielding areas based on the head grades and the associated metallurgical response for each defined geological area.

Furthermore, as illustrated in Table I, the early stages of the project are conducted to a low degree of accuracy and do not normally involve all the engineering disciplines (mechanical, electrical, civil, and structural). This results in a significant reduction in cost for these stages and the time taken to complete the work.
This allowed the metallurgical engineers the freedom to consider a variety of options early in the project with little or no input from the other engineering disciplines. The capital and operating cost estimates are, however, sufficiently accurate to allow for a comparison of the different process options. Options could be carried forward to the next stage if further resolution was required.

\section{Metallurgical test work}

Throughout the test programme, qualitative and quantitative mineralogical analysis was conducted on all of the samples. The results were related to the flotation results and provided valuable information for understanding the metallurgical response.

Initially, two composite samples were produced from drill cores. These samples were used to conduct the preliminary tests to develop the process design criteria for the order-ofmagnitude study. The test work included milling, gravity concentration, flotation, and leach tests.

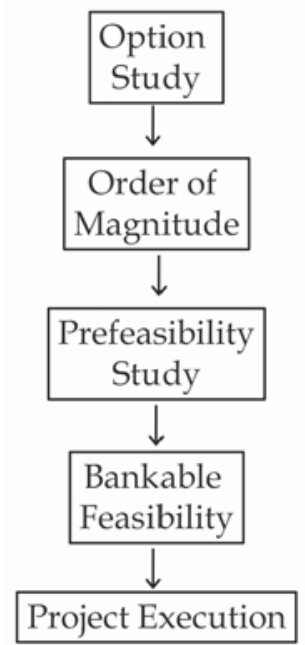

Figure 2-Stages in the development of the project 


\section{Development of a geometallurgical model for a copper concentrator}

The preliminary results provided valuable information for the geologists and defined the criteria for characterizing the samples. The subsequent reports from the geologists confirmed the varying oxidation highlighted in the literature (Hall, 2012), and three composites were generated for each of the two geological areas relative to sample depth, as discussed above. Milling and flotation tests were conducted on the composites and the results of the flotation tests related to the quantitative mineralogical analysis. This provided adequate information for the development of the fundamental processing flow sheet.

Variability flotation tests were carried out as per the proposed flow sheet on individual core samples to determine the variability in the flotation response and concentrate grades produced.

\section{Results and discussion}

\section{Mineralogy}

\section{Qualitative mineralogy}

Qualitative mineralogical analysis on various drill cores from the two deposits confirmed the geological observations. The predominant copper mineral observed in samples from depth (>35 m) was chalcocite with small amounts of bornite. Trace amounts of malachite were also observed in these samples. Liberation of the copper-bearing minerals did not appear to be a challenge.
Shallower samples contained increasing amounts of malachite, with samples shallower than 25 m containing varying concentrations of chrysocolla. The chrysocolla appeared to be associated with the malachite and liberation of the copper-bearing minerals would not pose a challenge.

Quartz was identified as the predominant gangue mineral, while plagioclase, mica, chlorite, and calcite were also identified. Calcite seemed to be more abundant in the upper zones than in the lower zones. Clay minerals occur in minor to trace amounts in some of the upper and middle samples. Calcite and chlorite are both high acid consumers, indicating that acid leaching may not be a process option.

\section{Quantitative mineralogy}

Following the initial qualitative mineralogy on the earlier drill cores, more detailed quantitative mineralogical investigations were carried out on the composite-by-depth samples and the variability samples.

The copper deportment in the two deposits is illustrated in Figure 3. It is clear that a large amount of chrysocolla is present in shallower samples that were submitted for test work. The middle zone appears to show a mixture of copper sulphide and oxide minerals, while negligible malachite and chrysocolla are evident in the lower zone.

\section{Preconcentration}

To allow for an informed choice with regard to the inclusion

\section{Table I}

\section{Level of engineering and degree of accuracy}

\begin{tabular}{|l|l|l|l|l|}
\hline Stage & Option study & Order of magnitude & Pre-feasibility \\
\hline Duration & Workshop & 2 weeks & 6 weeks & Bankable feasibility \\
\hline Expected accuracy & None & $30-40 \%$ & $25-30 \%$ & $5-10 \%$ \\
\hline Typically quoted accuracy & None & $-15 \%+30 \%$ & $-10 \%+25 \%$ & $-5 \%+10 \%$ \\
\hline Process engineering & Block flow diagrams & $\begin{array}{l}\text { Preliminary Process } \\
\text { Flow Diagrams (PFD's) }\end{array}$ & Decided PFD's \\
\hline Civil and structural engineering & None & Factored cost & $\begin{array}{l}\text { General Arrangement } \\
\text { Drawings (GA's) }\end{array}$ & GA's and detail \\
\hline Mechanical enginering & None & Factored cost & General arrangement & GA's, detail and tender process \\
\hline Electrical and control engineering & None & Factored cost & Factored cost \\
\hline
\end{tabular}
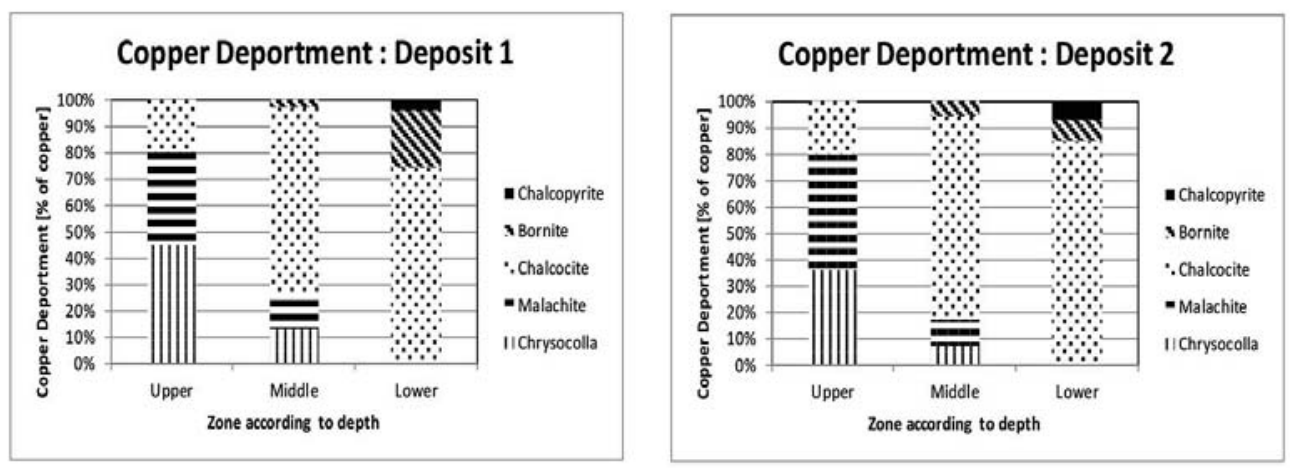


\section{Development of a geometallurgical model for a copper concentrator}

of a dense media separation (DMS) plant in the main process flow sheet, some heavy liquid separation (HLS) test work was carried out on the $-6 \mathrm{~mm}$ to $+1 \mathrm{~mm}$ fraction of the reef material.

Results showed that a DMS plant operating at a cut density of $2.7 \mathrm{t} / \mathrm{m}^{3}$ would theoretically reject $30 \%$ of the mass, with a loss of $9 \%$ of the copper to waste at a grade of $0.4 \%$ copper.

The DMS simulation indicated that due to the large amount of near density material, unstable operation of the DMS plant could be expected. The inclusion of a DMS plant in the flow sheet was therefore not recommended.

\section{Comminution}

Flotation tests were conducted at various grinds. The optimal grind was found to be $55 \%$ passing $75 \mu \mathrm{m}$. Comminution test work included the characterization of the ore through the determination of the crusher work index, rod and ball mill Bond Work indices, and drop weight tests to determine the fully/semi-autogenous (FAG/SAG) mill parameters.

Regrinding the sulphide concentrate to a $P_{80}$ of $38 \mu \mathrm{m}$ did not improve the recovery, but resulted in a significant improvement in copper grade. It was, however, noted that finer grinding of ores containing oxides resulted in a decrease in recovery, and this was attributed to the liberation and subsequent loss of chrysocolla that was originally associated with floatable species. This was confirmed in the qualitative mineralogical analysis.

\section{Flotation and leaching}

The initial test work on the composites of the two drill cores indicated that the recovery of the predominant copper-bearing mineral (chalcocite) did not pose a challenge and that recoveries in excess of $90 \%$ could be achieved at relatively high copper grades of up to $45 \%$. These results were achieved using a classical sulphide flotation reagent suite of potassium amyl xanthate (PAX) and a common water-soluble polyglycol ether (DOW 200) as frother.

Flotation tests on the shallower samples yielded a lower recovery. The mineralogical analysis revealed the presence of other copper minerals, particularly malachite and chrysocolla, in the flotation tailing.

The gangue acid consumption of the oxide ore was found to be excessively high, making it uneconomical to recover the oxide copper by acid leaching. It was decided to utilize a sulphidization step in the flotation circuit with the addition of NaHS to make the specific oxide minerals more susceptible to sulphide flotation (Kongolo et al., 2003; Newell et al., 2006; Raghavan et al., 1984).

In principle, the sulphidization flotation method is attractive, but the major disadvantages include potential depression of the sulphide minerals when sulphidization is used in excess, difficulty in controlling optimum dosage, and the fact that different oxide minerals respond differently to the addition of the sulphidizer.

Since sulphidization may result in depression of the sulphide minerals, and the sulphide and oxide minerals reacted differently to fine grinding of the rougher concentrate, it was decided to process the ore in two rougher-cleaner circuits in series, i.e. a sulphide circuit and an oxide circuit.
The chrysocolla was found to respond poorly to flotation, even with the addition of a sulphidizer. The mineralogical analysis revealed that the majority of the chrysocolla is recovered to a flotation concentrate through association with floatable species, e.g. malachite, that is recoverable under sulphidizing conditions.

\section{Solid-liquid separation}

Test work was done to determine the thickening and filtration characteristics of the tailings and concentrate.

It was found that the tailing was not difficult to filter and that high thickener underflow densities of up to $69 \%$ solids by mass could be achieved. Paste thickening tests showed that paste could be generated at $72 \%$ solids by mass.

\section{Process design}

\section{Option study}

The option study took the form of a one-day workshop that included a number of industry experts in the processing of copper. Presentations were given by geologists, mining engineers, minerals processing engineers, and hydrometallurgists on the status of the project and the findings of other studies on similar ores. Various options were considered and the most viable options compiled in an option study report for future reference. It was the opinion of the group that the most viable option, given the available data, would be a classical flotation plant utilizing a conventional crushing and grinding circuit.

\section{Order-of-magnitude estimate}

The process flow sheet recommended in the option study was considered and a capital and operating cost estimate generated.

The procedure required the development of the process engineering deliverables, i.e. the process flow diagrams, mass balance, and equipment sizing. Prices for major items of equipment were sourced from selected vendors and the team's database of prices. The direct capital cost of the concentrator was generated through a process of factorization by assuming that the cost of the mechanical equipment would make up $40 \%$ of the overall direct capital cost. At the time of compiling the estimate this assumption was proven valid for six similar flotation plants. The operating cost was compiled from first principles utilizing the team's experience and database, and where necessary input from the client project team.

This information was used by the mining engineers as an input to optimize the mine design, which in turn provided a revised input to the metallurgical team for the next stage.

\section{Pre-Feasibility Study}

The first set of test work confirmed earlier assumptions and it was decided that a flotation plant would be the most suitable process option. The geological and mineralogical data available at the time of the study indicated the presence of oxidized copper minerals, although the relative amount was negligible. A conventional sulphide copper circuit in a rougher, cleaner, and recleaner configuration was therefore selected for the flotation circuit. 


\section{Development of a geometallurgical model for a copper concentrator}

Test work did, however, indicate a benefit for a sulphide rougher concentrate regrind to a $P_{80}$ of $38 \mu \mathrm{m}$ and this was therefore included in the design.

Various plant circuit configurations were considered with the focus on the comminution and tailings dewatering circuits. A large difference between the rod mill Bond Work index $(21 \mathrm{kWh} / \mathrm{t})$ and the ball mill Bond Work index $(15 \mathrm{kWh} / \mathrm{t})$ at a limiting screen size of $150 \mu \mathrm{m}$ indicated the potential for a critical size build-up in a conventional SAG mill. Three scenarios were considered for the milling circuit, namely:

> Conventional three-stage crushing circuit followed by two-stage ball milling

> A conventional SABC circuit with a pebble crusher

> A top-size crusher and a high-pressure grinding roll (HPGR) followed by a conventional ball mill.

A cost analysis was conducted, and although the cost of the first two options were very close the first option was selected as the option of least risk. This would be reconsidered during the next phase of the project.

Given the shortage of water in the region, three options were considered for the processing of the flotation tailings. In each case the mode of tailings deposition was also considered in the generation of the capital and operating cost.

$>$ Belt filtration

- High-density thickened tailing (non-paste)

$>$ Paste thickening.

The cost of belt filtration and the associated material handling requirements for the filter cake eliminated this option. The negligible improvement in water consumption using paste thickening did not justify the high capital and operating cost associated with the pumping of paste. Therefore, high-density thickened tailings with a conventional tailings dam was selected.

The capital and operating costs were generated using a factorized approach as discussed under order-of-magnitudeestimate.

\section{Feasibility Study}

A large proportion of the metallurgical test work conducted during the Feasibility Study, concentrated on variability test work and locked cycle test work on the various ore types to confirm and support the assumptions made throughout the previous study. Extensive mineralogical analyses were included, which revealed the presence of varying amounts of oxidized copper minerals (malachite and chrysocolla).

Various alternatives were considered and an oxide flotation circuit employing a sulphidizing agent was then included in the design.

Based on the findings of the test work the comminution circuit in Figure 4 was proposed. The run-of-mine ore is processed through a primary crusher followed by a coarse ore stockpile. Coarse ore from the coarse ore stockpile is processed through a secondary and tertiary crusher circuit and proceeds to a fine ore stockpile ahead of the primary ball mill.

The primary and secondary ball mill discharge are combined in a common cyclone feed sump. The secondary ball mill is in closed circuit with a cyclone producing a cyclone overflow of $55 \%$ passing $75 \mu \mathrm{m}$.

The cyclone overflow is gravitated to the surge tank/conditioner ahead of the sulphide rougher flotation bank as illustrated in Figure 5. Sulphide rougher concentrate is re-milled to $80 \%$ passing $38 \mu \mathrm{m}$ prior to cleaner flotation. Sulphide recleaner concentrate is thickened prior to filtration. Sulphide cleaner tailings are pumped to the head of the oxide cleaner bank.

The sulphidization agent (NaHS) is added to the sulphide rougher tailing ahead of the oxide rougher bank. The oxide rougher concentrate is not re-milled and is processed in the oxide cleaner and recleaner bank. The oxide recleaner concentrate is thickened prior to filtration.

The oxide rougher tailing is thickened in a high density thickener to $68 \%$ solids by mass before being pumped to the tailing dam.

\section{Geometallurgical models}

The metallurgical inputs are critical in determining the viability of a new mining venture. The value of this data is important from two aspects:

> Determining the amount of valuable mineral that will be produced as a direct input into the financial model

$>$ Providing inputs in terms of metal recovery and associated costs into the mining plan and financial model in order to optimize the mining plan.

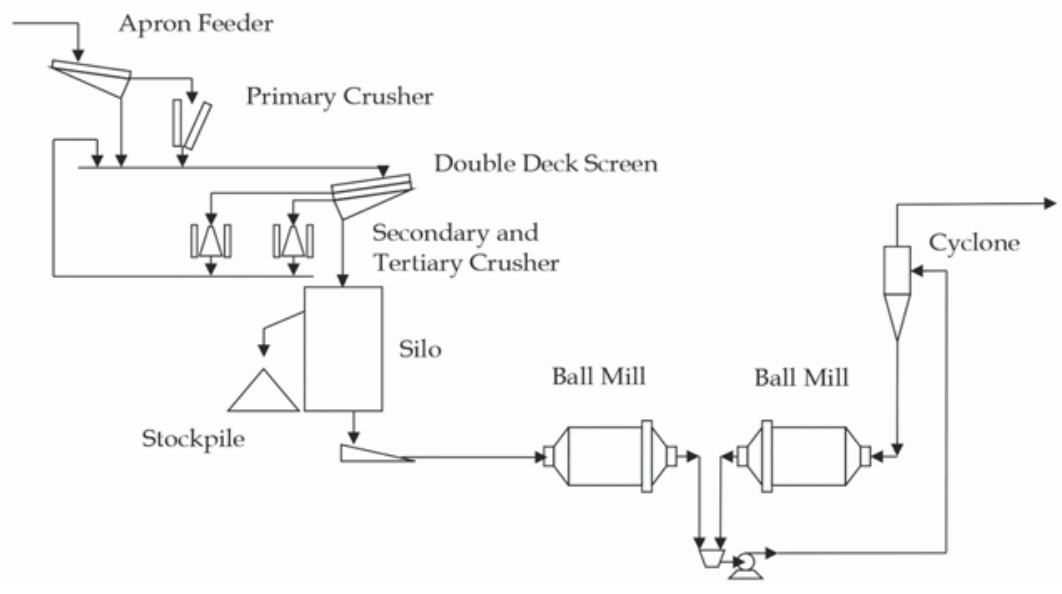




\section{Development of a geometallurgical model for a copper concentrator}

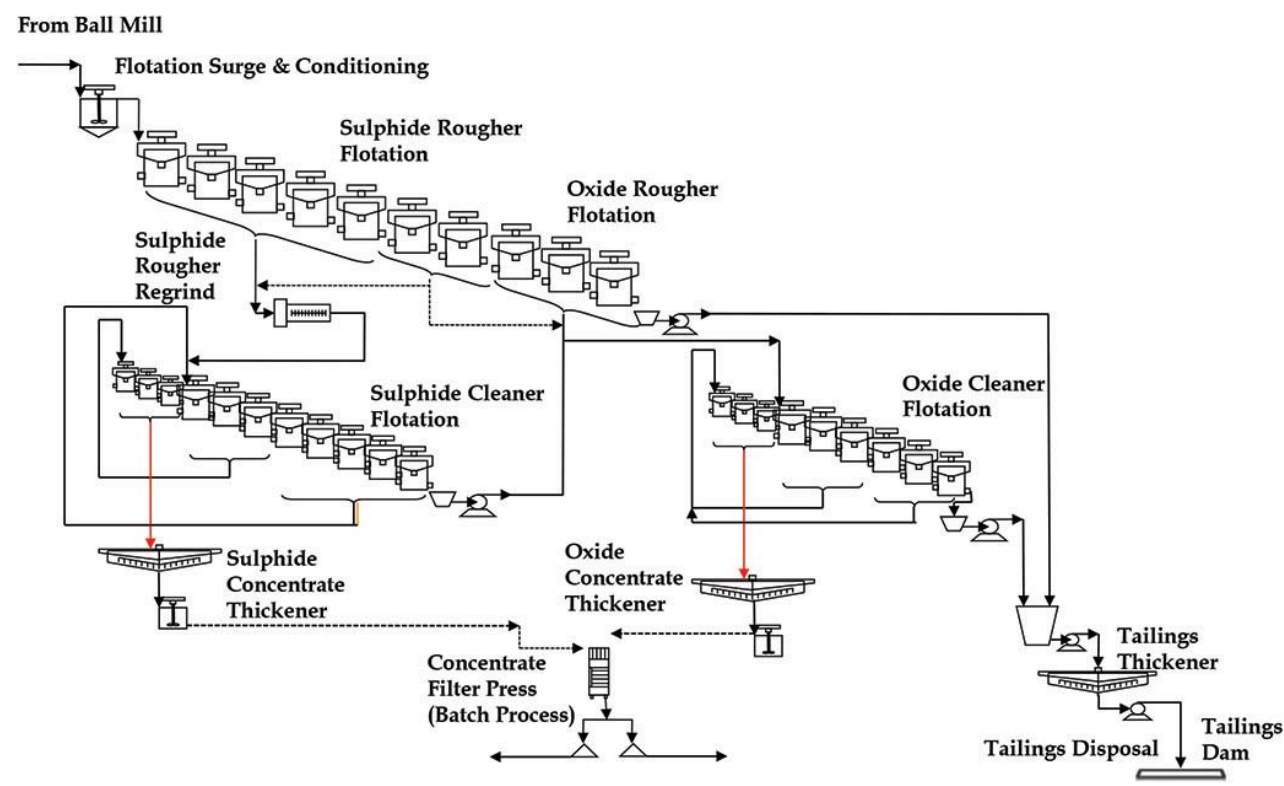

Figure 5-Proposed flotation circuit

In the initial phases of the project, discrete recovery predictions for each mining area, based on the initial batch test work, were used to estimate overall recovery for the mining plan and financial model. As more flotation and mineralogical data became available, a more detailed model forecasting the recovery, concentrate grade, and concentrate tonnage was developed.

\section{Development of the models}

A relationship between the sulphur-to-copper ratio and copper recovery became evident from test work on samples from the different zones. It became necessary to further investigate this relationship by conducting tests on individual samples within the range of sulphur-to-copper ratios for these zones (typically between zero and $30 \%$ ).

The relationship illustrated in Figure 6 was observed and a linear regression of the data generated. It is interesting to note that for the lower sulphur-to-copper ratios the recoveries for Area 2 are significantly higher than the corresponding recoveries for Area 1. This supports the observation that the copper minerals in Area 1 tend to exhibit a higher degree of oxidation compared to Area 2.

A similar relationship was observed between the mass ratio reporting to the sulphide concentrate and the sulphurto-copper ratio. This relationship was important in determining the overall grade of the concentrate produced.

A comprehensive analysis was done of the sulphide and oxide concentrates for the upper, middle, and lower zones for each mining area. Based on the zone that was being considered in the mining plan, a sulphide concentrate grade and oxide concentrate grade could be derived. This overall concentrate grade could then be calculated from the mass ratio reporting to sulphide or oxide concentrate discussed above.

\section{Concentrate production model}

The mining plan compiled by the geologists and mining engineers was used to generate a forecast of the metal production and associated cost. The algorithm derived from the above relationships was included in the mining plan and the financial model, together with the capital and operating costs.

The algorithm can be summarized as follows:

> Calculate the mass of copper recovered to concentrate using the mining head grade and tonnage, and the recovery from the recovery model

> Calculate the fraction of concentrate reporting to the sulphide concentrate using the linear relationship with the sulphur-to-copper ratio

> Apply the copper concentrate grade based on the sulphur-to-copper ratio to determine the grade of the sulphide and the oxide concentrate

> Calculate the masses of sulphide and oxide concentrate produced.

This algorithm was used to predict the copper production and the concentrate grade for the life of mine. The copper production and copper grade for the first 24 months of operation are illustrated in Figure 7.

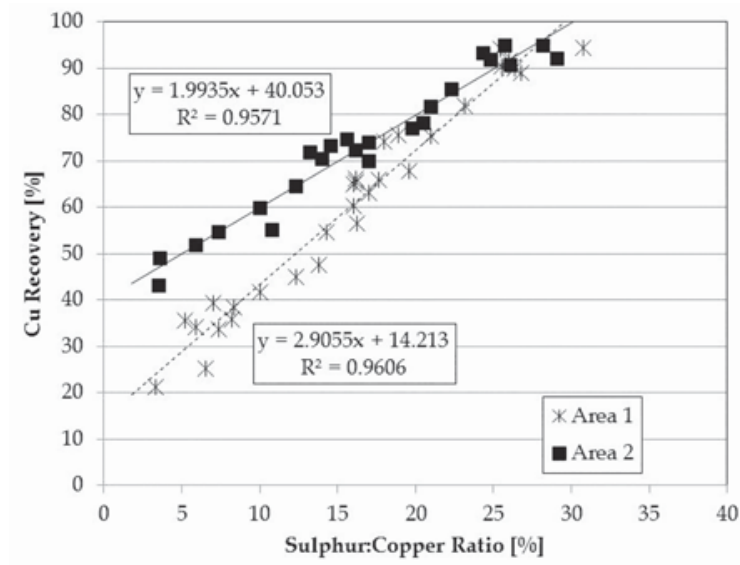

Figure 6-Relationship between Cu recovery and sulphur-to-copper ratio 


\section{Development of a geometallurgical model for a copper concentrator}

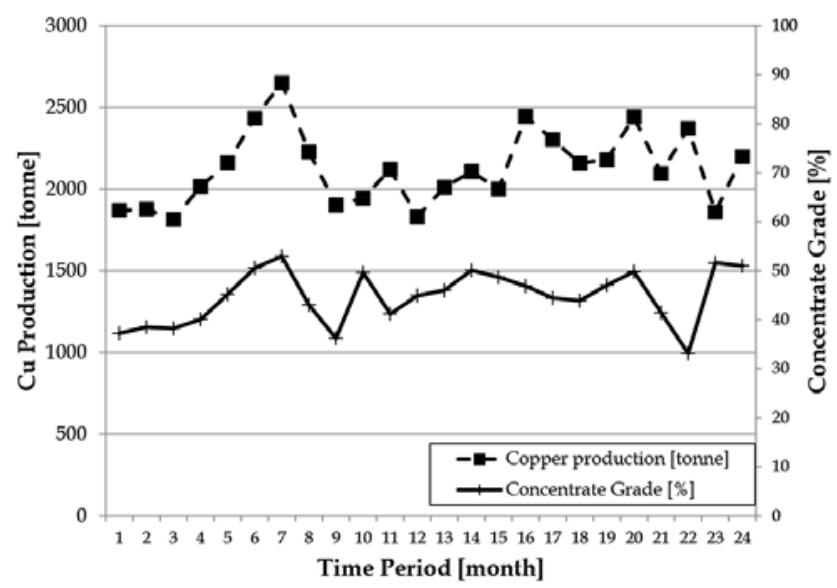

Figure 7-Forecast concentrate grade and production

Use of the metallurgical model in the integrated mining plan yielded an additional 1.2 Mt of mineable ore from an overall $19.5 \mathrm{Mt}$ reserve. This is equivalent to an increase of $6 \%$ in the mineable reserves.

\section{Quality of the metallurgical test work}

\section{Comparison of assays}

Assaying of the drill cores had begun well before the metallurgical test work commenced at Mintek in Randburg, South Africa. As the client was based in Australia, it was decided to submit the geological samples to the Genalysis laboratory in Australia.

A comparison was completed on the head assays for each of the drill core samples for the Mintek assays and the Genalysis assays. Applying the paired t-test analysis confirmed that the two data-sets were not significantly different at a 95\% confidence level. This finding was significant as it indicated that the model developed using the Mintek analyses could be applied to the mining model developed in Australia using results from Genalysis.

\section{Quality of flotation test work}

A number of routine checks were completed to determine the quality of the flotation test work, e.g. comparison of the reconstituted head grades and the assayed head grades of the samples for the various flotation tests as illustrated in Figure 8. The paired t-test analysis of the two data-sets found that there was no significant difference at a $95 \%$ confidence level.

\section{Conclusions}

The mineralogy of the Kalahari Copper Belt is interesting and presents challenges, particularly in the recovery of copper in the form of copper oxides, where recoveries can be as low as $30 \%$. Further fundamental test work needs to be completed to identify more efficient means of recovering the copper, particularly in the presence of high acid-consuming species.

Detailed mineralogical analysis prior to and during the metallurgical test work added a significant amount of value in that it allowed the metallurgists to relate the results of the test work to the mineralogical observations. Furthermore, the mode of occurrence of the copper lost to tailings could be

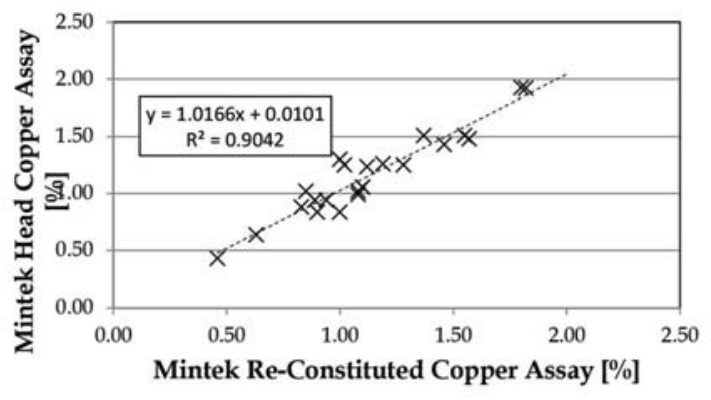

Figure 8-Comparison between Mintek and Genalysis assays

identified and addressed in the process design.

Variability test work proved to be critical in accurately defining the metallurgical characteristics of the deposit, thereby ensuring that ore variability was recognized in the mining plan.

Cooperation and regular communication between the various disciplines on the project proved to be critical in ensuring the success of the project and minimizing the risk to the client. As illustrated in this case study, the combination of the discipline models resulted in ore previously classified as 'uneconomical' being reclassified and deemed mineable, making the project a more viable proposition.

\section{References}

Hall, W.S. 2012. Geology and paragenesis of the Boseto copper deposits, Kalahari Copper Belt, North West Botswana. MS thesis, Colorado School of Mines.

Kongolo, K., Kipok,a M., Minanga, K., and Mpoyo, M. 2003. Improving efficiency of oxide-cobalt ores flotation by combination of sulphidisers. Minerals Engineering, vol. 16. pp. 1023-1026.

Newell, A.J., Skinner, W.M., and Bradshaw, D.J. 2006. Restoring the floatability of oxidized sulfides using sulfidisation. International Journal of Mineral Processing, vol. 84. pp. 98-107.

Raghavan S., Adamec E., and Lee L. 1984. Sulfidisation and flotation of chrysocolla and brochantite. International Journal of Mineral Processing, vol. 12. pp. 173-191. 